\title{
Density model for aqueous glycerol solutions
}

\author{
Andreas Volk ${ }^{1}$ (1) Christian J. Kähler ${ }^{1}$
}

Received: 16 March 2018 / Accepted: 19 March 2018 / Published online: 3 April 2018

(c) The Author(s) 2018

\begin{abstract}
Glycerol is used in many applications of science and daily life as it is cheap and biologically non-invasive. In science, aqueous solutions of glycerol are commonly used for experimental investigations as their density can be adapted by changing the glycerol content in the solution. Although the density of aqueous glycerol solutions has been measured precisely since more than a century, current models show a deviation from measured data of up to $2 \%$. In this work we present an analytical expression to accurately calculate the density of aqueous glycerol solutions. The presented empirical model is validated in the range between 15 and $30^{\circ} \mathrm{C}$ and has a maximum deviation of less than $0.07 \%$ with respect to measured data. This improves the accuracy of current models by more than one order of magnitude. By knowing the temperature and glycerol content of the solution, its density can be simply calculated with the presented model. A Matlab function is provided in the supplementary material to allow a simple implementation in other scientific work.
\end{abstract}

\section{Introduction}

Glycerol is used in many applications within the scientific fields of fluid mechanics, chemistry, medicine, and biology. In daily life glycerol is commonly used in pharmaceutical and personal care products, as well as an anti-freeze and in food industry, because it is cheap and non-toxic (Ayoub and Abdullah 2012). In scientific work the exact determination of the density of aqueous glycerol solutions is important. By mixing glycerol with water, the density of the solution at room temperature can be adapted in the range from 1000 $\mathrm{kg} / \mathrm{m}^{3}$ (pure water) to $1260 \mathrm{~kg} / \mathrm{m}^{3}$ (pure glycerol). This possibility of adapting the liquid density is why glycerol is used in many scientific fields in particular in fluid mechanics and biotechnology. A specific example for the application of this technique in fluid mechanics is the matching of the liquid density to polymer particles, which allows them to follow the streamlines. This property can be used in measurement technologies to determine the structure of a flow

Electronic supplementary material The online version of this article (https://doi.org/10.1007/s00348-018-2527-y) contains supplementary material, which is available to authorized users.

Andreas Volk

andreas.volk@unibw.de

1 Institut für Strömungsmechanik und Aerodynamik, Universität der Bundeswehr München, Werner-Heisenberg-Weg 39, 85577 Neubiberg, Germany field (Adrian and Westerweel 2011; Raffel et al. 2018). In biotechnology, glycerol density gradients allow to separate biological material by centrifugation (Hansen et al. 1987). Due to the various applications mentioned above, densities of aqueous glycerol solutions have been measured since more than a century. Whereas first measurements by Gerlach (1884) and Strohmer and Gerlach (1885) were accurate to four significant digits, several detailed investigations on the properties of aqueous glycerol solutions have been published later in the early 20th century by Washburn and West (1926) and Timmermans (1935), as well as by Bosart and Snoddy (1927) and Bosart and Snoddy (1928) and determined the density of glycerol and its aqueous solution with a precision up to five significant digits. A summary of tables on glycerol measurements can be found in a publication by the Glycerine Producers' Association (1963). On the other hand, a precise formula to calculate the density based on temperature and glycerol content has not yet been presented. An attempt to summarize these measurements in a formula has been presented by Cheng (2008). However, in that work, the density of the solution is wrongly calculated using the mass fractions of the solutes instead of the volume fractions. Moreover the effect of volume contraction is not taken into account. In the work presented here, these aspects are corrected to develop a model for the the density of aqueous glycerol solutions that precisely fits with the measured data of Bosart and Snoddy (1928). 


\section{Density relation for aqueous glycerol solutions}

Assuming an ideal solution, its density $\rho_{\mathrm{s}}$ is given by

$\rho_{\mathrm{s}}\left(T, \phi_{i}\right)=\sum_{i=1}^{N} \rho_{i}(T) \phi_{i}$

where $N$ is the number of components, $T$ the temperature value in ${ }^{\circ} \mathrm{C}, \phi_{i}$ the volume fraction of the $i$ th component, and $\rho_{i}(T)$ its temperature-dependent density. However, Eq. (1) does not take into account the volume contraction, an effect that is typically small but occurs for most liquid mixtures and leads to a solution volume $V_{\mathrm{s}}$ that is smaller than the sum of the component volumes $\sum_{i} V_{i}$ (Prigogine et al. 1957). To set up a model with high accuracy, this effect is also taken into account in this work. Thus, the volume contraction coefficient $\kappa$ is introduced as the ratio:

$\kappa=\frac{1}{V_{\mathrm{s}}} \sum_{i} V_{i}$

By analyzing measured data of aqueous glycerol solutions, it can be found that $\kappa$ not only depends on the volume fraction of glycerol, but also on the temperature of the solution (Bosart and Snoddy 1928). With the volume contraction the density of an aqueous glycerol solution is given by

$\rho_{\mathrm{s}}\left(T, \phi_{\mathrm{g}}\right)=\kappa\left(T, \phi_{\mathrm{g}}\right)\left[\rho_{\mathrm{g}}(T) \phi_{\mathrm{g}}+\rho_{0}(T)\left(1-\phi_{\mathrm{g}}\right)\right]$,

where $\phi_{0}$ and $\phi_{\mathrm{g}}$ are the volume fractions of water and glycerol and $\rho_{0}(T)$ and $\rho_{\mathrm{g}}(T)$ the densities, respectively. As the mass fraction $w_{i}$ is more commonly used than the volume fraction $\phi_{i}$ to describe the amount of the components in a solution, the conversion:

$\phi_{\mathrm{g}}=\left[1+\frac{\rho_{\mathrm{g}}(T)}{\rho_{0}(T)}\left(\frac{1}{w_{\mathrm{g}}}-1\right)\right]^{-1}$

is used in the following. The resulting expression for the density of an aqueous glycerol solution is then

$\rho_{\mathrm{s}}\left(T, w_{\mathrm{g}}\right)=\kappa\left(T, w_{\mathrm{g}}\right)\left[\rho_{0}(T)+\frac{\rho_{\mathrm{g}}(T)-\rho_{0}(T)}{1+\frac{\rho_{\mathrm{g}}(T)}{\rho_{0}(T)}\left(\frac{1}{w_{\mathrm{g}}}-1\right)}\right]$.

\section{Model for the density of aqueous glycerol solutions}

The model presented in this work is based on experimental data which is shown in Table 1 of the supplementary material where the density of aqueous glycerol solutions $\rho_{\mathrm{s}}$ was measured by Bosart and Snoddy in a temperature range between 15 and $30{ }^{\circ} \mathrm{C}$ for glycerol weight fractions between 0 and $100 \%$ with an uncertainty $\Delta \rho_{\mathrm{s}} \approx 0.1 \mathrm{~kg} / \mathrm{m}^{3}$ (Bosart and Snoddy 1928). Based on this data, a model will be developed in this work to describe the density of aqueous glycerol solutions. The model uses the density of pure water $\rho_{0}$ (Linstrom and Mallard 2005; Wagner and Pruß 2002) and pure glycerol $\rho_{\mathrm{g}}$ (Bosart and Snoddy 1928) to calculate $\rho_{\mathrm{s}}$. The uncertainties of the measured densities of the pure components are $\Delta \rho_{0} \approx 0.01 \mathrm{~kg} / \mathrm{m}^{3}$ and $\Delta \rho_{\mathrm{g}} \approx 0.1 \mathrm{~kg} / \mathrm{m}^{3}$. With Eq. (2) and the given uncertainties, the uncertainty of the volume contraction coefficient is $\Delta \kappa \approx 0.0002$ according to linear error calculation.

The densities of the pure liquids can be approximated with the empirical expressions:

$\rho_{0}(T)=1000\left(1-\left|\frac{T-3.98}{615}\right|^{1.71}\right) \frac{\mathrm{kg}}{\mathrm{m}^{3}}$

for water and

$\rho_{\mathrm{g}}(T)=(1273-0.612 T) \frac{\mathrm{kg}}{\mathrm{m}^{3}}$

for glycerol (adapted from Cheng (2008) to fit the data of Linstrom and Mallard (2005) and Bosart and Snoddy (1928), respectively). Equation 6 describes the temperature dependent density of water where the maximum deviation from the measured data is less than $0.3 \mathrm{~kg} / \mathrm{m}^{3}(0.03 \%)$ in the temperature range between 0 and $100{ }^{\circ} \mathrm{C}$. For glycerol, the temperature dependent density is given by Eq. (7) and the maximum deviation from the measured data is less than $0.4 \mathrm{~kg} / \mathrm{m}^{3}(0.03 \%)$ in the temperature range between 15 and $30^{\circ} \mathrm{C}$. For pure liquids $\kappa$ has to be exactly one. To guarantee this it can be approximated by the function

$\kappa\left(T, w_{\mathrm{g}}\right)=1+A \sin \left(w_{\mathrm{g}}^{1.31} \pi\right)^{0.81}$,

where $A$ is the temperature dependent coefficient

$A=1.78 \times 10^{-6} T^{2}-1.82 \times 10^{-4} T+1.41 \times 10^{-2}$.

Equations (8) and (9) where determined based on the measurements of Bosart and Snoddy (1928). Figure 1 shows a comparison between $\kappa$ calculated by the model given in Eq. (8) and the same coefficient determined based on the measured data as a function of glycerol content and temperature. The maximum deviation of $\kappa$ from the measured data is 0.0004 which is only by a factor of 2 higher than the calcuated uncertainty based on the measurements.

The density of aqueous glycerol solutions is calculated by substituting Eqs. (6)-(8) into Eq. (5). When 


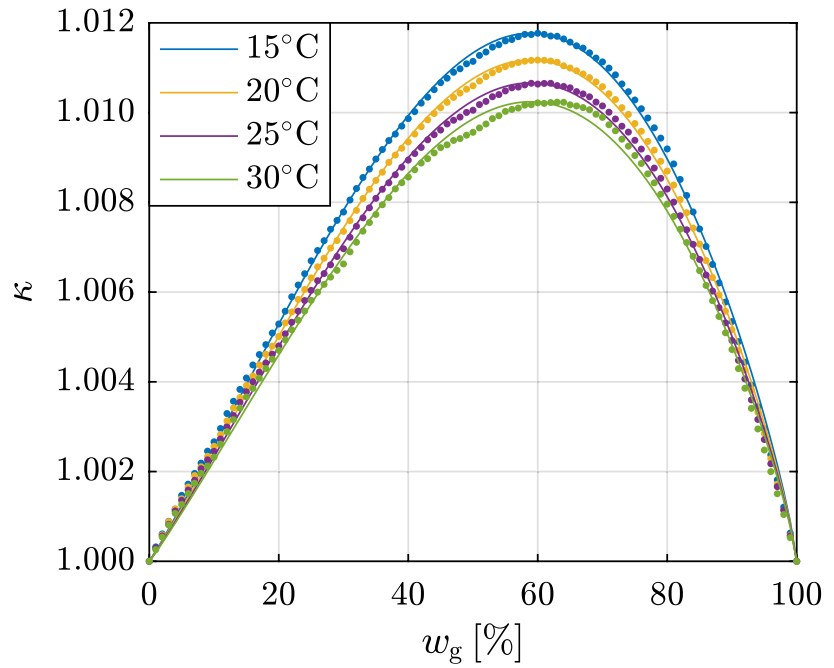

Fig. 1 Coefficient $\kappa$ of aqueous glycerol solutions as a function of glycerol mass fraction $w_{\mathrm{g}}$ and Temperature $T$. Data points where calculated from the data of Bosart and Snoddy (1928) (dotted lines). Model for contraction is given by Eq. (8) (solid lines). The maximum deviation of the model from the measured data is approximately 0.0004. A maximum of the volume contraction can be observed for glycerol mass fractions of about $60 \%$. With increasing temperature, $\kappa$ is decreasing according to Eq. (9)

comparing the results with the measurements which are given in Bosart and Snoddy (1928) in the temperature range between 15 and $30^{\circ} \mathrm{C}$, the maximum deviation between model and measured data is less than $0.7 \mathrm{~kg} / \mathrm{m}^{3}$ $(0.07 \%)$. In comparison, the commonly used model of Cheng (2008), which does not take into account volume contraction shows a maximum deviation from measured data of about $2 \%$. A more recent but less known work by Cristancho et al. (2011) is using the Jouyban-Acree model (Jouyban et al. 2004) to estimate the density of aqueous glycerol solutions and achieved results with a maximum deviation from measured data of about $0.4 \%$. The model presented in this work is, therefore, strongly improving other density models of aqueous glycerol solutions and is much closer to the measurement uncertainty of $0.01 \%$.

Figure 2 shows a comparison of the model presented in this work with the models of Cheng (2008) and Cristancho et al. (2011), respectively. The measured data of Bosart and Snoddy (1928) is also shown in the figure. To enable an easy implementation of the above results in other scientific work, a matlab function with the model is provided in the supplementary material. An online calculator for the density and viscosity of aqueous glycerol solutions is provided by Chris Westbrook (http://www. met.reading.ac.uk/ sws04cdw/viscosity_calc.html). The tables in the supplementary material show a comparison between the measured data (Supplementary Table 1) and the model (Supplementary Table 2) as well as calculated
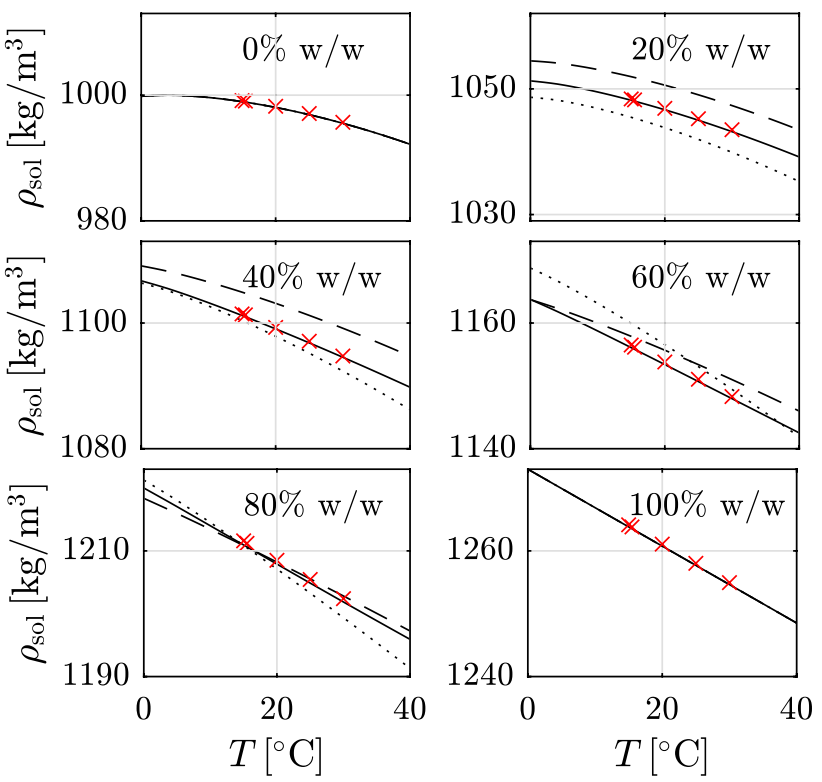

Fig. 2 Comparison between density measurements and analytical density models of aqueous glycerol solutions with various glycerol contents by weight (w/w). Solid lines represent the model given in Eq. (5), dashed lines the model of Cheng (2008), dotted lines the model of Cristancho et al. (2011), and the cross-markers the measured data by Bosart and Snoddy (1928). Comparing the models with experimental data in the temperature range between 15 and $30^{\circ} \mathrm{C}$, the models of Cheng and Cristantcho et al. show a clear deviation of up to $2 \%$. In contrast the model presented in this work that takes into account the volume contraction has a maximum deviation from the measured data of less than $0.07 \%$ and is much closer to the measurement error of $0.01 \%$

densities of aqueous glycerol solutions at typical lab temperatures between 15 and $29^{\circ} \mathrm{C}$ (Supplementary Tables 3, $4,5)$.

Acknowledgements Abundant discussions and help from Chris Westbrook, University of Reading, UK especially in the approximation of the volume contraction Eq. (8) is greatly acknowledged. The authors acknowledge financial support by the German Research Foundation (DFG) Grant KA 1808/17-1.

Open Access This article is distributed under the terms of the Creative Commons Attribution 4.0 International License (http://creativeco mmons.org/licenses/by/4.0/), which permits unrestricted use, distribution, and reproduction in any medium, provided you give appropriate credit to the original author(s) and the source, provide a link to the Creative Commons license, and indicate if changes were made.

\section{References}

Adrian RJ, Westerweel J (2011) Particle image velocimetry. Cambridge University Press, Cambridge

Ayoub M, Abdullah AZ (2012) Critical review on the current scenario and significance of crude glycerol resulting from biodiesel industry towards more sustainable renewable energy industry. Renew Sust Energ Rev 16:2671-2686 
Bosart L, Snoddy A (1927) New glycerol tables. Ind Eng Chem 19:506-510

Bosart L, Snoddy A (1928) Specific gravity of glycerol. Ind Eng Chem 20:1377-1379

Cheng NS (2008) Formula for the viscosity of a glycerol-water mixture. Ind Eng Chem Res 47:3285-3288

Cristancho DM, Delgado DR, Martínez F, Abolghassemi Fakhree MA, Jouyban A (2011) Volumetric properties of glycerol+ water mixtures at several temperatures and correlation with the JouybanAcree model. Rev Colomb Cienc Quim Farm 40:92-115

Gerlach GT (1884) Ueber Glycerin, specifische Gewichte und Siedepunkte seiner wässrigen Lösungen sowie über einen Vaporimeter zur Bestimmung der Spannkräfte von Glycerinlösungen (German) [On glycerol, specific gravity and boiling points of its aqueous solutions as well as on a vaporimeter for the determination of the tension forces of glycerol solutions]. Chem Ind 7:277-287

Glycerine Producers' Association (1963) Physical properties of glycerine and its solutions. Glycerine Producers' Association, New York

Hansen J, Schulze T, Moelling K (1987) RNase H activity associated with bacterially expressed reverse transcriptase of human T-cell lymphotropic virus III/lymphadenopathy-associated virus. J Biol Chem 262:12393-12396
Jouyban A, Fathi Azarbayjani A, Barzegar-Jalali M, Acree J (2004) Correlation of surface tension of mixed solvents with solvent composition. Pharmazie 59:937-941

Linstrom P, Mallard W (2005) Thermophysical properties of fluid systems. NIST standard reference database 69

Prigogine I, Bellemans A, Mathot V (1957) The molecular theory of solutions. North-Holland, Amsterdam

Raffel M, Willert CE, Scarano F, Kähler CJ, Wereley ST, Kompenhans J (2018) Particle image velocimetry. Springer, Heidelberg

Strohmer F, Gerlach GT (1885) Ueber die Gehaltsbestimmung wässriger Glycerinlösungen (German) [On the content dedetermination of aqueous glycerine solutions]. Fresen J Anal Chem 24:106-112

Timmermans J (1935) Travaux du bureau international d'étalons physico-chimique - VII - Étude des constantes physiques de vingt composés organiques (French) [Work of the international bureau of physical and chemical standards - VII - study of the physical constants of twenty organic compounds]. J Chim Phys 32:501-526

Wagner W, Pruß A (2002) The IAPWS formulation 1995 for the thermodynamic properties of ordinary water substance for general and scientific use. J Phys Chem Ref Data 31:387-535

Washburn EW, West CJ (1926) International critical tables of numerical data, physics, chemistry and technology, vol 3 